\title{
Kohanimed vepslaste vaimse kultuuri valgustajatena
}

\author{
Irma Mullonen
}

\begin{abstract}
Teesid: Vepsa rahvaluulest on kogutud ainult killukesi ja teated eepilisest pärimusest puuduvad täiesti. Üldse on vepslaste vaimset elu peegeldav sõnavara säilinud väga puudulikuna. Selle põhjuseks tuleb lugeda rahva karmi saatust, sest juba teise aastatuhande alguses sattusid vepslased vene tugeva mõju alla, mis jättis oma jälhe nii elatusaladesse, ühiskondlikku ellu kui ka kultuuri. Artiklis analüüsitakse vepslaste kohanimesid, lootes et toponüümika suudab oma eripärast hoolimata valgustada muinasja elu materjaalse külje kõrval ka rahva vaimset traditsiooni.
\end{abstract}

Märksõnad: Karjala, toponüümika, vepsa

Vepslaste rahvakultuur on mõneski mõttes terra incognita. Kui asjale läheneda läänemeresoome vaatepunktist, tunduvad vepsa mütoloogiat puudutavad teated väga napid. Rahvaluulest on kogutud ainult killukesi. Täiesti puuduvad teated vepsa eepilisest pärimusest. Vepslaste vaimset elu peegeldav sõnavara on kõike kokku võttes säilinud väga puudulikuna. Põhjuseks pole vepslaste pärimuse vaesus, vaid rahva karm saatus. Juba teise aastatuhande alguses sattusid vepslased tugeva vene mõju alla. See haaras endasse rahva elu kõik tahud - elatusalad, ühiskondliku elu ja kultuuri. Õigeusk tõi kaasa uued tavad ja rituaalid, tõrjudes samal ajal kõrvale vepslaste muistsed traditsioonid. Nii näiteks on vepslased peaaegu tervikuna üle võtnud vene pulmakombed. Esitati venekeelseid pulmalaule ja -itke, ise nende sisust aru saamata. Koos õigeusuga võeti üle ka kalendrikombestik. Igivanade 
vepsa pühade elemente on säilinud vaid osakestena ja needki on ortodokssesse kalendrisse laiali puistatud (Vinokurova 1994).

Sellises olukorras on väärtuslik mistahes vaimse kultuuri kohta käiv informatsioon, isegi kui see pärineb rahvakultuuri uurimise seisukohalt sekundaarsetest allikatest. Kohanimed on just selline infoallikas. Sellest saadav teave ei tule siiski otseselt esile. See on tabatav alles siis, kui mõistetakse toponüümika seaduspärasusi. Aunuse ja Viena-Karjala kohanimede võrdlus osutab, et Viena-Karjala toponüümika on märgatavalt kujundlikum. Siin leidub loodusnähtuste personifikatsioone ja palju võimsaid mütoloogilisi mõisteid, mis kajastavad inimese ja looduse suhteid traditsioonilises eluviisis. Selle kultuuri tunnusjooni võib Karjala põhjapiirkondades kohata veel nüüdki. Alles mõne aastakümne eest olid need üldised.

Aunuse Karjala livvi ja lüüdi murrete kõnelejate ning vepslaste toponüümika on silmapaistvalt argisem. Oma üldtoonilt on see praktiline, kajastades järjekindlalt seda, mis on majanduslikult otstarbekas. Ehk piisab ühest silmahakanud näitest. On teada, et kohanimedes peegeldub taimestik. Lähem eritlus osutab siiski, et taimenimede kasutamine toponüümikas on valikuline. Rohketest taimenimedest on vepsa toponüümikas juurdunud üksnes mõned. Need on sellised, millest inimestel on olnud praktilist kasu. Üpris tagasihoidlik vehk (soovõhk, calla palustris) on toponüümikas olnud tähtsam kui paljud muud taimed, sest seda on kohalik rahvas kasutanud rahvameditsiinis ja jahu lisandina näljaaastatel. Just see on Vehkajärvede ja -jõgede sageduse põhjuseks vepslaste poolt asustatud ja neile lähedastel vene aladel. Kohaliku elanikkonna majanduselu on dikteerinud vepsa toponüümika suuna. Majanduselu aluseks on olnud maaviljelus, mis on suurel määral kujundanud vepslaste maailmapilti ja selle väärtusi.

Kohanimede hulgas eristub siiski selgelt rühm, mis ei mahu otstarbekuse põhimõttel rajanevasse üldisesse skeemi. Selle rühma moodustavad kohanimed, kus esinevad loomanimed. Vepsa toponüümika väldib täielikult kesksemaid jahiloomi - oravat, põtra ja jänest. Tähtsaimad jahilinnud teder ja metsis esinevad geograafilistes nimedes harvemini kui näiteks kurg (Kurgso, Kurgjärv, Kurgoja, Kurgnem Kurgsoo, -järv, -oja, -neem) või luik (Düucoidärv, Juucnoja - Luikjärv, -oja). Vepslastele näivad meelepärased olevat samb-algusega kohanimed. Konna nime rohket kasutamist toponüümikas ei saa seletada praktilisest vaatepunktist. Teisiti öeldes ei sobi kohanimede loetelu kokku saakloomade loeteluga. Miks see nii on? Kõik need juhud, mis ei seletu ümbritseva tegelikkusega, on ilmselt vepsa mütoloogia 
järelkajad. See räägib kõnesolevate loomade funktsioonist vepslaste maailmapildis kütikultuuri ajastul, mil saakloom oli omal moel inimühiskonna loomulik osa (MNM).

Vepsa toponüümikas esineb eriti loomi, keda tuntakse soome-ugri algmütoloogias. Need on kurg, luik, konn ja karu. Viimast kohtab rohketes hüdronüümides, näiteks Kondijärv, Kondioja, Kondisara. Tähelepanuväärsel moel esineb valdav osa kondi-algusega hüdronüümidest veekogu ülemjooksul või veelahkme lähistel. Selline konkreetne seos annab lisatunnistust kõnealuste kohanimede mütoloogilisest algupärast. Nagu teada, on soome-ugri pärimused paigutanud karu sageli ülailma asukaks.

Laadoga, Äänisjärve ja Valgejärve vahelisel järvedealal asunud muistsete vepslaste elu on olnud seotud veekogudega. Jõed ja järved on olnud ainukesed ühendusteed. Igapäevane majandustegevus - jahipidamine, kalastamine, põlluharimine ja metsakasutus on toimunud kõige sagedamini kindla vesikonna piires. Vesikonna piir on ühtlasi olnud ka kasutatava ala piir. On ehk võimalik, et kohaliku rahvastiku mütoloogiline kompetents on mõistnud kohaldada maailma müütilisele kaardile omased nähtused - üla- ja allmaailma ning nende piiri paikkonna tõelise kaardiga, näiteks vesikondadega. Selle kohaselt on karu kui ülailma esindaja andnud oma nime vesikondade ülemjooksul asetsevaile järvedele ja jõgedele.

Teadagi on see oletus hüpoteetiline. Siiski on siin asju, mis köidavad uurija meelt. Näiteks on olemas geograafilisi nimesid, mida võib vaadelda ühelt poolt metafoorina, piltliku kohanimena, kuid teiselt poolt võivad need sisaldada sügavaid tähendusi ja osutuda müütilistel arusaamadel põhineva toponüümilise süsteemi kildudeks.

\section{Maailmasammas kohanimedes}

Läänemeresoome mütoloogias eksisteerib eriline maailmasammas, mille all mõistetakse taevavõlvi. Sellel on mitmeid nimetusi, nagu taevanael, maasammas või taevanaba. Viimane tähendab maailmasamba liikumatut ülaosa, Põhjanaela. Kalevala-runode mütoloogias kujutletakse taevanaba kõrge mäena, mille tipp toetub Põhjanaelale (Harva 1948: 42-48).

Need seigad on Lõuna-Vepsa toponüümika kontekstis tähtsad. Lõuna-Vepsas on nimelt kaks mäge, mille nimi on Taivaznaba (taevanaba). On põhjust oletada, et sama tähendus ja kujund on ka 
Nabmägi- ja Nabamägi-nimede aluseks. Ka viimatimainitud mäed asuvad Lõuna-Vepsa alal.

Eelmainitud näited osutavad, et läänemeresoome maailmapildi traditsiooniline aines - soome taivaannapa, vepsa taivaznaba - on tuntud olnud ka vepslaste seas. Toponüümika on talletanud ja säilitanud seda puudutava teabe tänapäevani välja. Teisalt on eelmainitud kohanimed näiteks selle kohta, kuidas on mütoloogilist maailma seostatud paikkonna tegeliku kaardiga.

Maailmasamba mõistet on läänemeresoome traditsioonis (soomlastel, eestlastel, saamidel) väljendatud eespool juba nimetatud terminitega (maa)sampa või (maa)sammas, mis oli taevast toetav kuldne sammas ja mille tipus oli Põhjanael. Taevavõlv keerles ümber Põhjanaela. Oletatakse, et Kalevala kuulus sampo kuulub sampa-või sammas-sõnade perre (SKES). Tõsi küll, tänapäeva vepsa keel seda sõna ei tunne. Kesk-Vepsas leidub siiski terve kohanimede rühm, mille algusosaks on samb-või sambas-tüvi (Sambjärv, Sambasjärv, Samboja, Sambasso). Sellele lisaks on nüüdseks juba venestunud piirkondades rohkesti Sambasozero-nimelisi toponüüme. Oleks ehk põhjendatud käsitleda neid kohanimesid mütoloogilise termini ja sellele vastava vepsa mõiste muistse olemasolu kinnitusena.

Tuleb tunnistada, et kõnealused näited ei ole sama veenvad kui esimesena mainitud taivaznaba. Kui lõunavepsa Taivaznaba seostub mägede ja kõrgendikega, mis kinnitab tajutavalt sõna semantilist tähendust, siis samb-tüve võib kohata sagedamini järvede nimedes. Niisiis puudub kohanime ja termini sisu vahel tajutav ja mõjuv ühtsus.

Ometi pole põhjust jätta neid huvitavaid samb-algulisi kohanimesid tähelepanuta. Kui analüüsida sellenimeliste järvede geograafilist asendit, võib täheldada, et need paiknevad eranditult vesikondade piirialadel, vesikondi üksteisest eraldavate vööndite ehk seljandike äärtes. Geograafilise seiga kõrval on tähtis ka see, et mõnes läänemeresoome keeles, nimelt soome ja eesti keeles pole sammas-sõnal ainult mütoloogiline, vaid ka päris argine tähendus - sammas, post, samuti piirikivi, piiripost (SKES).

Sõna niisugune semantika sobib suurepäraselt maastikupilti ja on vesikondade piiril olevate järvede nimena täiesti loomulik. Meie ees on piltlik näide sellest, et muinasvepslaste vesikondade piirid olid ühtlasi territooriumide piirid. Kui muinasvepslased ka ei tundnud tänapäevaks kadunud samb-sõna maagilist tähendust, tundsid nad vähemalt selle ühiskondlikku tähendust ja koos sellega ka piiripostide institutsiooni. 


\section{Püha-algulised kohanimed}

Küllap väärib siinses vaatluses tähelepanu ka püha-sõnaga algavate kohanimede süsteem, eriti jõgede ja järvede nimed. Meenutagem, et tänapäeva vepsa keeles on pühä-sõna saanud sekundaarse tähenduse - paast - mis on õigeusklikku päritolu. Pühadele eelnev aeg on ortodoksse käsituse kohaselt seotud paastumisega. Vepsa pühä algupärane tähendus on sama muude läänemeresoome keelte (karjala, soome, eesti) vastavate sõnadega. See on säilinud ka vepslaste nüüdsete ja muistsete territooriumide kohanimede venekeelsetes tõlgetes, kus kohtab sageli svjato-nimelisi jõgesid ja järvi (Svjatreka, Svjatuha, Svjatozerka).

Võib märgata, et pühä-algulised kohanimed järgivad sama seaduspärasust nagu samb-algusega nimedki. Needki järved ja jõed paiknevad kõik vesikondade vahelistel aladel. Algul mainitud kolme suurjärve vahelisel alal on kõik pühad järved ja jõed vesikondade servmised. Nende taga on veelahe ja algab uus vesikond. Teisiti öeldes on pühad järved piiriveed, mis eraldavad oma püha võõrast ja tundmatust.

Sellisena ei ole vepsa traditsioon muu läänemeresoomelise seisukohalt mingi erand. On ju teada, et soome ja eesti püha-algulised kohanimed järgivad rauaajast pärinevaid sugukondade territooriumide piire ja on niiviisi mõnes mõttes piiripostideks (Suvanto 1972: 54). Meie kasutuses olevate teadete põhjal võib tõdeda, et püha-algusega hüdronüüme on ka karjalaste ning Karjala venestunud aladel, eriti Puudožis ja Arhangelski oblasti lääneosas.

Niisugusel kohanimede süsteemil on vaieldamatult suur ajalooline ja kultuuriline tähtsus. Muistsete kaartide ja kirjalike allikate puudumisel aitab see tabada hõimude valduses olnud maade piire ja kaardistada vepsa asuala piire, samuti Äänisjärve, Laadoga ja Valgejärve vahelise territooriumi asustuslugu. Samal ajal peitub "pühas" toponüümikas sõna teine, maagiline tähendus, mis tuleb vahetule esile pühä-lekseemi kaudu.

Vaadeldud näited on kindel tunnistus sellest, et toponüümika sisaldab erilist rahva vaimset kultuuri avavat teavet. Oma nappusest hoolimata on see ainestik üliväärtuslik, sest vepslaste vaimne kultuur on säilinud vaid üksikute irraliste osadena.

Mõnel juhul on kohanimed osutunud sitkemaks kui pärimus, mille jääneid nad on säilitanud. Toponüümika on näiteks talletanud teavet vepslaste muistsest puudekultusest. Sellest kõneleb kohanimeaines, 
näiteks lõunavepsa Jumapedai (Jumalamänd, Jumalapedajas), Ojati vepslaste Pühäpedai (Pühapedajas) ja Punopedai - mänd (pedajas), mille tüvi on keerdus. Punopedai esineb väga sageli Ojati kandi kohanimedes ja tuleb vepsa punoda-sõnast, mis tähendab punumist või pööramist. Niisugustel keerdus puudel usuti olevat maagiline kaitsev jõud. On tähelepanuväärne, et ainult mändidel on pärisnimed, mis võib kajastada männi erilist osa sealsete asukate uskumustes. Tähelepanekute põhjal võib tõdeda, et samalaadseid toponüüme on ka Äänisneeme ja Puudoži piirkonnas. Ka seal on mänd olnud erilisema tähelepanu all.

\section{Surnud kohanimedes}

Huvitavaid esivanematekultuse säilmeid võib märgata koumišt-algusega kohanimedes (vepsa koumišt tähendab kalmistut). Seda tüüpi toponüümika on levinud eriti Kapša- ja Lid-jõgede ülemjooksu aladel Lõuna- ja Kesk-Vepsas. Nendega on seotud uskumusi, mis viitavad kõnealuste kohtade austamisele. Niisugused on näiteks jutud leedulaste (harvem tatarlaste) rüüsteretkedel tapetud ja maha maetud kohalikest elanikest, teatud puude langetamise keeld, nendest paikadest öösel möödumise ees tuntav hirm (sest ilmuda võisid kummitused) ning komme käia kõnealustes kohtades vaid teatud tähtpäevadel. Seega annavad kümned niisugused meie päevini säilinud kohanimed võimaluse näha kunagise laialt levinud esivanematekultuse jälgi Lõuna- ja Kesk-Vepsas.

Tõdetagu, et vastav kultus esines ka muudel vepsa aladel. Erinevates murretes oli sel siiski oma terminoloogia, mis võib olla keelest täiesti kadunud ja säilinud ainult kohanimedes. Nii näiteks on Valgejärve vepslastelt kirja pandud kahe metsasalu nimedena Panad. Nimi viitab müütilistele esiisadele (vrd vepslaste lähedastes Põhja-Venemaa piirkondades säilinud pärimusega võõrastest vallutajatest ehk panidest). Neid jutte uurinud Vladimir Pimenovi järgi võib terminit seostada vepsa väljendiga panda (maha) - maha matta (Pimenov 1965).

Ojati piirkonna vepslastel tuntakse kohanime Ročinkoumad - Rootsi kalmud või hauad - ja muistendit selle paikkonna Roč-nimelisest hiiglasest, kes oli ennevanasti seal võimsate vaskväravate taga elanud. Vepsa keeles on sõna roč (ročo) säilinud vaid mõnes murrakus ja tähendab ristimata last. See on huvipakkuv sõna. Sellel on sama algupära kui karjala ja soome sõnal ruotsi - rootslane, soomlane, luterlane. 
Et vepslastel pole olnud otseseid kontakte soomlastega, ongi nende keeles toimunud eriti huvitav roč-sõna tähenduse areng. Sõna on hakanud tähendama võõrasse usku kuulujat ja ristimatut. On tõenäoline, et kristluse vastuvõtmise järel on sellele eelnenud ajal pühaks peetud inimesi hakatud pidama ristimatuteks ehk ebakristlikku maailma kuuluvateks. Võib-olla on just niiviisi saanud alguse Ojati piirkonna kohanimed Ročinkoumad, Ročinmägi ja Ročinkorb (Rootsikõrb, -laas; kõrb-sõna tähendas eesti keeleski varem põlismetsa. Tõlk).

\section{Problemaatiline hiis-sõna}

Kohanimede põhjal võib oletada, et vepsa ala idaservas, Äänise ja Valgejärve veelahkmel elavad Šimjärve vepslased on kasutanud esiisade kummardamise paikade kohta hiž-sõna (tüvi hide-). See sõna on säilinud ainult vepslaste endise ja praeguse asuala arvukates kohanimedes, kuid keelest muidu täiesti kadunud. Hiž-algusega kohanimed on näiteks Hižgärv, Hižoja, Hitkar ja Hitte (Hiisjärv, Hiisoja, Hiiekari, Hiietee).

Nii rohke hiž-algusega kohanimede hulk osutab veenvalt, et hiiemõiste on ka vepslastel vanasti tuntud olnud. Mis on võinud olla selle tähendus? Sõna on tuntud ka muudes läänemeresoome (soome, eesti ja karjala) keeltes. Neis keeltes on sellel lai tähendusväli alates vanapaganast, kuradist, metshaldjast kuni kalmistu, paganate pühapaiga või püha metsasaluni välja. Soomes 1970. aastal tehtud uurimistöös on osutatud nende tähenduste ühtekuuluvusele. Uurimuses on samuti kartografeeritud tähenduste arengut igas sugulaskeeles eraldi. Sõna on saanud kuradi mõistega seotud tähenduse. Eelkristlikul ajal on see aga olnud etnilise usundi nähtus ja tähistanud selle atribuute kultuskohti ja -objekte.

Kui lähtuda sellest, et $h i z ̌$-sõna on püsima jäänud kohanimedesse, oleks seda loogiline pidada vepslaste kultuskohtade tähistajaks. Kohanimi tähendab ju teatud koha ja geograafilise objekti ühtsust. Niisuguseks paigaks võis väga hästi olla suguvõsa matusepaik ja seda ümbritsev või selle kohale kasvanud metsasalu, millest hiljem sai kultuse objekt. Selles mõttes on iseloomulik, et mõnes hiž-nimega paigas oli vana kultusetraditsioon säilinud lausa viimaste aegadeni. On teada mitmeid juhtumeid, kus õigeusu kirik, tavaliselt kabel, oli ehitatud kohale, mis kannab nime Hižnem (Hiisneem) või Hižmägi (Hiiemägi). Kõigele lisaks kõnelevad need seigad etnilise usundi ja 
kristlike pühapaikade päritavusest. Nõnda tõestab toponüümika uurimine, et hižz-termin ja sellega seotud rituaalid on Šimjärve vepslastel tuntud olnud juba eelkristlikul ajal.

Lõpuks tõdetagu, et selles ülevaates pole puudutatud kaugeltki kogu seda vepslaste vaimse kultuuri kohta käivat teavet, mida toponüümika on suutnud talletada ja säilitada kuni meie päevadeni. Üldse ei ole käsitletud kohanimede teket seletavaid muistendeid. See oleks täiesti omaette uurimuse teema. Samuti vääriks omaette käsitlemist see, kuidas avaldub toponüümikas vepslaste eelkristlikesse jumalatesse puutuv teadmine ja muu vaimne kultuur.

Toponüümika suudab oma eripärast hoolimata valgustada muinasaja elu materiaalse külje kõrval ka rahva vaimset traditsiooni. Tulemusrikast uurimistööd võikski jätkata mütoloogilise kaardi ja paikkonna tegeliku kaardi võrdlemisega.

Soome keelest tõlkinud Kristi Salve

Originaal: Mullonen, Irma 1994. Paikannimistö vepsäläisten henkisen perinteen valottajana. Heikkinen, Kaija \& Mullonen, Irma (toim). Vepsäläiset tutuiksi. Kirjoituksia vepsäläisten kulttuurista. Joensuun yliopiston Karjalan tutkimuslaitoksen julkaisuja 108. Joensuu: Joensuun yliopisto. 


\section{Kirjandus}

Harva, Uno 1948. Suomalaisten muinaisusko. Porvoo, Helsinki: WSOY.

MNM = Токарев С. А. (peatoim) 1987-1988. Мифы народов мира. Энциклопедия в 2 томах. Москва.

Pimenov 1965 = Пименов, В. В. Вепсь. Очерк этнической истории и генезиса культуры. Москва \& Ленинград: Наука.

SKES = Tanner, Satu \& Cronstedt, Marita \& Toivonen, Yrjö \& Itkonen, Erkki (koost) 1955-1981. Suomen kielen etymologinen sanakirja. Lexica Societatis Fenno-Ugricae XII. Helsinki: Suomalais-Ugrilainen Seura.

Suvanto, Seppo 1972. Satakunnan ja Hämeen keskiaikainen rajelaitos. Tampereen yliopiston historian laitos. Monistesarja B no. 3. Tampere: Tampereen yliopisto.

Vinokurova 1994 = Винокурова, И. Ю. Календарные обычаи, обряды и праздники вепсов (конеи XIX - начало XX вв.). Санкт-Петербург: Наука. 


\title{
Summary
}

\section{Place names as reverberations of the Veps' intangible culture}

\author{
Irma Mullonen
}

Keywords: Karelia, toponymy, Vepsian

Only fragments have been collected of Vepsian folklore, and records of epic heritage are entirely non-existent. In general, the survived vocabulary related to the Veps' intellectual life is extremely incomplete. The reason for this is the grim fate of the nation, as already at the beginning of the second millennium, the Veps came under strong Russian influence, which left its imprint on their sources of subsistence, social life and culture. The article analyses Vepsian place names, trying to find in toponymy, besides the material side of ancient life, also indications of the nation's intellectual tradition. 


\section{Uurimusi vepsa rahvausust}

Koostaja ja toimetaja Madis Arukask

http://www.folklore.ee/rl/pubte/ee/sator/sator16/

ISSN 1736-0323 (veebiväljaanne)

ISBN 978-9949-544-96-7 (veebiväljaanne)

ISSN 1404-2011 (trükis)

ISBN 978-9949-544-95-0 (trükis)

DOI: 10.7592/Sator.2016.16

Tartu 2016

Sarja toimetaja: Mare Kõiva

Koostaja ja toimetaja: Madis Arukask

Keeletoimetaja: Asta Niinemets

Kaas ja kujundus: Andres Kuperjanov

Kaanefoto: Madis Arukask

Küljendus: Diana Kahre

HTML: Diana Kahre

Trükis ilmunud: Uurimusi vepsa rahvausust.

Koostaja ja toimetaja Madis Arukask. SATOR 16. Tartu 2016

Raamatu ettevalmistamist ja väljaandmist on toetanud Eesti Teadusagentuur (grandid nr 7385 ja 9271) ning Eesti Vabariigi Haridus- ja Teadusministeerium (projekt IUT 2-43). Raamatu toimetamist ja vormindamist toetas Euroopa Liit Euroopa Regionaalarengu Fondi kaudu (Eesti-uuringute Tippkeskus), see on seotud Eesti Teadusagentuuri institutsionaalse uurimisprojektiga IUT 22-5. Trükitud Eesti Kultuurkapitali toetusel.

E-raamatu valmimist toetas: EKKM14-344 Eesti keele, kultuuri ja folkloori kasutusalade laiendamine ja tutvustamine elektroonilistel infokandjatel.

(C) 2016 EKM Teaduskirjastus

(C) 2016 Eesti Folkloori Instituut

() 2016 EKM FO rahvausundi ja meedia töörühm

(C) 2016 autorid 